EGU21-3498, updated on 01 Apr 2021

https://doi.org/10.5194/egusphere-egu21-3498

EGU General Assembly 2021

(c) Author(s) 2021. This work is distributed under

the Creative Commons Attribution 4.0 License.

\title{
Comparison of different infiltration methods for flood numerical analysis: modelling the 19 June 1996 extreme event of Cardoso (Alpi Apuane, Italy)
}

\author{
Michele Amaddii ${ }^{1}{ }^{2}$, Enrico D'Addario ${ }^{1}$, Leonardo Disperati ${ }^{1}$, and Pier Lorenzo Fantozzi ${ }^{1}$ \\ ${ }^{1}$ Università di Siena, Dipartimento di Scienze Fisiche, della Terra e dell'Ambiente, Siena, Italy \\ ${ }^{2}$ Università di Firenze, Dipartimento di Scienze della Terra, Firenze, Italy
}

As the climate changes are expected to generally increase the hydrogeological hazard, a better knowledge of the catchment-scale response to intense rainfalls is a relevant issue. Hence, in this work, different approaches of infiltration processes estimation are analysed within hydrological modelling of the extreme rainfall event which involved in 1996 the Cardoso area (southern Alpi Apuane, Tuscany, Italy).

On June 19, 1996, a convective supercell storm produced extreme rainfall rates $(478 \mathrm{~mm} / 12 \mathrm{~h}$ with maximum intensity of $158 \mathrm{~mm} / \mathrm{h}$ ) within a restricted area of the southern Alpi Apuane. The heavy rainstorm principally affected the Cardoso river watershed, where shallow landslides and debris flows were triggered in the steep slopes of the low-order hydrographic network covered by thick unconsolidated materials. Consequently, severe hyperconcentrated flows destroyed the Cardoso village, with 13 deaths and hundreds million Euros damages.

The FLO-2D flood routing model was used for the numerical modelling of the infiltration processes occurred during the event, by implementing both the SCS-CN method and the Green-Ampt (GA) equation. FLO-2D is a combined hydrologic-hydraulic model, in which there is no need to separate rainfall/runoff and flood routing and spatially varying rainfall/infiltration may be simulated. The main advantage of the GA model arises in the temporal variation of the rainfall intensity, which is not considered in the $\mathrm{CN}$ model.

In north-western Tuscany and especially in the Cardoso basin, the Authors have available a large set of engineering geological data obtained by field surveys performed under the coordination of the Geomatics lab of the University of Siena. Namely, the field saturated hydraulic conductivity (Ks) and soil depth measurements were used to implement both the GA equation (I) and the CN method (II, III). For each lithological unit, the continuous maps of the soil depth and the Ks were obtained by integrating the field data with the landforms extracted by processing a set of morphometric DTM derivatives. Regarding the CN method, the Hydrologic Soil Groups (HSG) were determined following the procedure proposed by the USDA-NRSC (Hydrology National Engineering Handbook, version 2009) (II), and by applying the subjective interpretation criteria (III) which does not consider the values of Ks and soil depth.

Methods (I) and (II) show similar results and are consistent with the historical literature data and information, considering three relevant transects close to the village, as well as with post-event 
field evidences. The results obtained by applying the method (III) are strongly conditioned by the subjective assignment of the HSG and they can be different in terms of peak discharge, flood wave arrival time and maximum water level, if compared to (I) and (II). Moreover, the spatial distribution of soil depth and Ks allows a comprehensive representation of the hydrological-morphological framework of the Cardoso catchment. 